\title{
Carta Pastoral
}

Equipo Pastoral, Escuela de Teología ${ }^{1}$

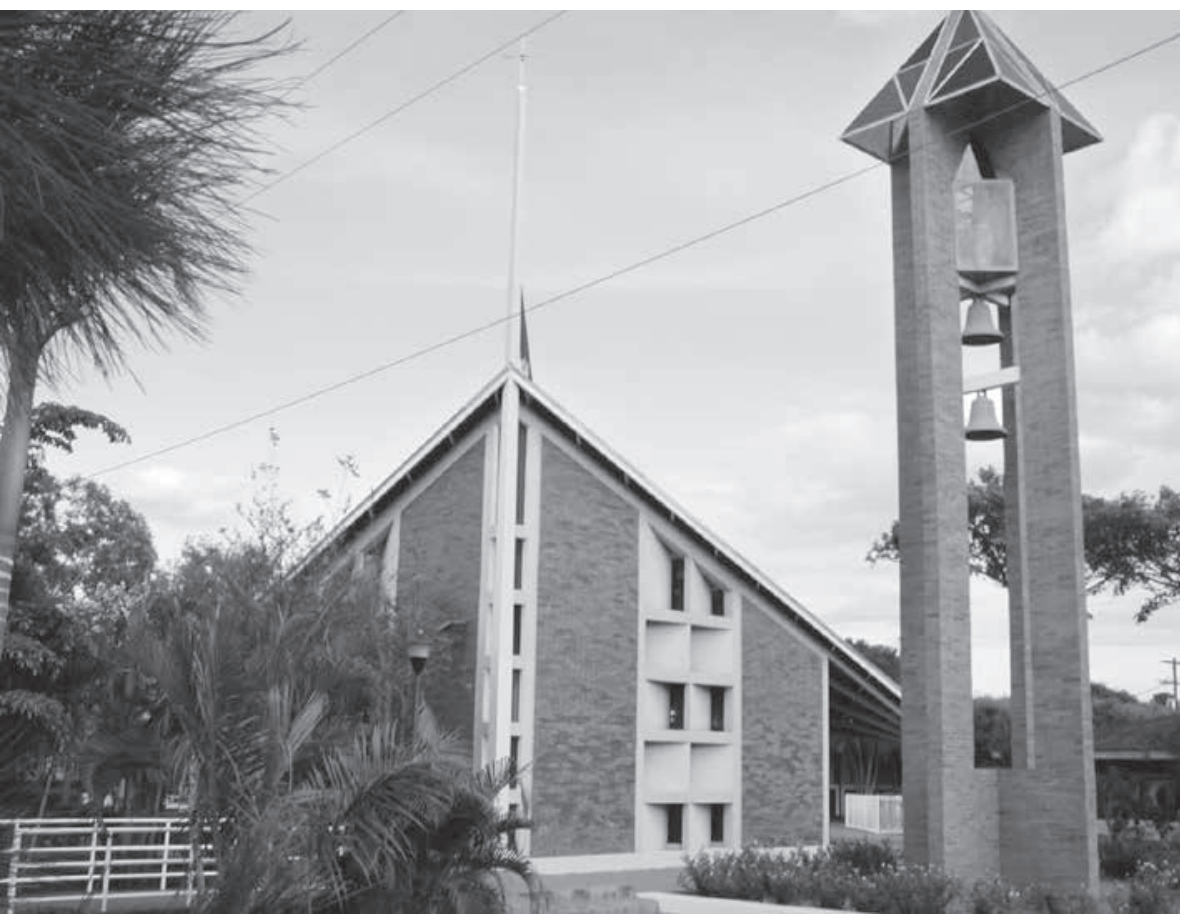

$\mathrm{H}$ ablando en el contexto de la UPOLI, expresamos con mucho beneplácito que el día jueves 16 de enero celebramos nuestra Liturgia de Gratitud al Señor, pidien-do su bendición por el inicio de este nuevo año de labores 2014. Hemos retornado con ánimos renovados por la gracia de Dios y con nuestros corazones agradecidos, conscientes que la UPOLI, su ministerio y obra es de Jesucristo. Él es la inspiración de la UPOLI como proyecto educativo al Servicio del reino de Dios y del pueblo nicaragüense.

Jesús nos enseña la forma de gobernar y dirigir que le agrada a Dios cuando en su palabra nos dice: "Sabéis que los que son tenidos por gobernantes de la naciones se enseñorean de ellas, y sus grandes ejercen sobre ellas potestad. Pero no será así entre vosotros, sino que el que quiera hacerse grande entre vosotros será vuestro servidor,

\section{RESUMEN}

Esta carta pastoral está dirigida particularmente a la comunidad universitaria de la UPOLI; también la hacemos extensiva a quienes están en eminencia: Gobierno, instituciones públicas y privadas. Nuestros jóvenes, mujeres, niños y personas de la tercera edad, necesitan un ambiente de mayor atención humana en la calidad de los servicios, en la creación de riquezas materiales y espirituales, así como también en lo concerniente a la distribución de éstas, con justicia social y amor cristiano.

Palabras clave: Liturgia, desafío, comunidad, estudiantes, espiritualidad.

\section{ABSTRACT}

This Pastoral Letter is particularly addressed to the university community of the UPOLI; it is also extended to those who are prominent figures: Government, public and private institutions. Our young people, women, children and elderly people, need an environment of greater human attention in quality of the services, in the creation of material and spiritual wealth, as well as in its distribution with social justice and Christian love.

Key words: Liturgy, challenge, community, students, spirituality.

1 Universidad Politécnica de Nicaragua (UPOLI). 
y el que de vosotros quiera ser el primero será siervo de todos. Porque el Hijo del Hombre no vino para ser servido, sino para servir y dar su vida en rescate por muchos". (Marcos 10:42-45).

El lema de la UPOLI, "Sirviendo a la Comunidad", fue atinadamente acogido en el seno de nuestra universidad desde sus orígenes. Así lo reconoció y enfatizó en su discurso del 16 de enero del presente año, nuestra Rectora Dra. Lidya Ruth Zamora. Ella subrayó como desafío fundamental continuar "Sirviendo a la Comunidad" con sentido de unidad, humildad y de responsabilidad, tal como lo ordena nuestro Señor Jesucristo. Por tanto:

Exhortamos a los trabajadores de la universidad, a nosotros mismos, a la fraternidad y humildad como valores cristológicos relevantes, con el sentido profundo del respeto y reconocimiento de la dignidad humana de las personas a quienes servimos, en especial a los/las estudiantes. A trabajar con eficiencia ("como al Señor"), en equipo, haciendo sinergia con los compañeros/ as de trabajo, para hacer más productivas las jornadas laborales.

Esta exhortativa la hacemos extensiva a quienes están en eminencia: Gobierno, instituciones públicas y privadas. Nuestros jóvenes, mujeres, niños y personas de la tercera edad, necesitan un ambiente de mayor atención humana en la calidad de los servicios, en la creación de riquezas materiales y espirituales, así como también en lo concerniente a la distribución de éstas, con justicia social y amor cristiano. En este sentido, el genio poético declara:

"Si el labrador afanoso no cultivara los campos, no habría en el mundo trigo ni pan con qué alimentarnos.

Si el albañil por su parte, piedra y mezcla manejando no construyera las casas, no habría donde albergarnos.

Si el sastre y el zapatero se nos cruzaran de brazos,

quedaríamos desnudos y andaríamos descalzos. Nuestras aptitudes varias son para más obligarnos,

a prestarnos mutua ayuda y a querernos como hermanos.
No menosprecies a nadie que todos valemos algo.

Nadie se basta a sí mismo, todos nos necesitamos"

\section{Ezequiel Solana \\ Poeta Español.}

Solamente con comunidades unidas e integradas, por y para el mejor desarrollo humano, se podrá cerrarle espacios al desencuentro, a la soledad y la exclusión. Solamente con comunidades que desarrollen la espiritualidad de la vida, como fundamento de su ser y quehacer, se dará lugar a la cooperación mutua, al diálogo y a la convivencia; a la justicia, la paz, la equidad y al bien común.

Exhortamos a vivir la fe en Cristo Jesús, quien nos ha señalado el camino del Reino de Dios. Este camino debe ser la reserva moral para los trabajadores; sean obreros de la construcción, de la limpieza, docentes, de la salud, profesionales de todas las áreas y de cualquier otro tipo.

Cuando los líderes políticos o religiosos fallan, cuando nuestras propias fuerzas nos fallan, la fe en Cristo Jesús nos debe impulsar a seguir adelante, a no claudicar. Esta experiencia de fe en Jesucristo atraviesa nítidamente el ámbito individual, familiar, eclesial y social de quienes nos comprometemos con la esperanza del Dios vivo del cual nos da testimonio la Biblia. Nos motiva a los más altos niveles de compromiso con la fe que profesamos y la labor o profesión que ejercemos.

La fe y esperanza en el Señor, nos debe impulsar al deseo de superación constante, a no vacilar ni desmayar ante el impacto de frustraciones sociales y las injusticias que enfrentamos, ante la miseria material y espiritual que observamos en las calles. Debemos revestirnos de motivación y buen ánimo, conscientes que todas estas cosas implican un importante desafío moral, ético, espiritual y laboral que nos debe mover a los más elevados niveles de responsabilidad, eficiencia y excelencia en todo lo que hagamos como institución educativa al servicio del pueblo Nicaragüense, así como también nos debe motivar a la búsqueda de la sabiduría y la inteligencia que viene de Dios, al cual debemos honrar, obedecer, amar y glorificar con la pertinencia y calidad de nuestro servicio humano, educativo y académico ante las necesidades y demandas del país y de la sociedad Nicaragüense. 
Exhortamos a todos (as) en general al respeto, de los recursos naturales, los bosques, las aguas y las riquezas ambientales con las que Dios nos ha dotado. Si leemos la parábola del buen samaritano (Lucas 10: 25-37) y tratamos de contextualizarla, entenderíamos hoy, que nuestro prójimo está representado en los niños y niñas nacidos (as) y por nacer, a quienes desde ya les estamos privando de un ambiente saludable, de un planeta que nosotros hemos recibido de nuestro Creador, hermoso y bello, con la encomienda de preservar esa belleza y hermosura, (Génesis 1:27-28). El prójimo también podríamos considerar que es nuestro propio planeta. Sin embargo, a causa del egoísmo, la ambición desmedida, la avaricia, la no atención de los valores cristianos y humanos, lo hemos vuelto cada vez menos habitable. Seremos buenos mayordomos o administradores cuando utilicemos bien todo aquello que se nos ha confiado, especialmente la naturaleza y la propia sostenibilidad de sus recursos.

Jesús siempre nos interpela por medio de preguntas: “¿Qué está escrito en la Ley? ¿Cómo lees?" (Lucas 10:26). De este modo nos está preguntando: ¿Cómo vives? ¿Cómo trabajas? Trabajar no siempre es servir. Sólo el trabajo asumido como un servicio de calidad que respeta la integridad humana, animal y de los recursos naturales y la toma de conciencia y respeto a estos elementos, con vistas al futuro de las nuevas generaciones, se podrá considerar en realidad como una actitud y buen servicio comunitario.

Exhortamos a la evaluación constante comenzando por nosotros mismos. Desde el comienzo Dios, como Creador del Universo, nos enseña a evaluar nuestra obra. La obra poética de la creación en el Génesis nos relata: "Dijo Dios: Sea la luz. Y fue la luz. Vio Dios que la luz era buena..." Génesis 1:3.4. Dios evaluando su trabajo creador.

Evaluar en el proceso, es la mejor forma de corregir, mejorar y asegurar que nuestro servicio a la comunidad sea eficiente y pertinente.

Integrar la teoría y la práctica, además de ser un desafío, es nuestra mejor herramienta, ante el peligro de perder el amor y la pasión de servir con la calidad y coherencia que Dios nos enseña.

Este año debe ser un año que comience con nuevos y mejores logros, que comience con el logro de superarnos a nosotros mismos. Un logro importante debe ser marcar la diferencia entre quien pretende figurar y quien realmente desea, aportar y trabajar con dedicación y sentido de responsabilidad, entre quien cumple sólo por el afán del salario que recibe, y quien trabaja con sentido ético y la satisfacción por servir a la comunidad humana, que representa la mayor riqueza de la nación.

Por estas razones, las palabras de Jesús de Nazaret son pertinentes ayer, hoy, mañana y siempre: "Porque el Hijo del Hombre no vino para ser servido, sino para servir y dar su vida en rescate por muchos". (Marcos 10:45).

Los/las integrantes de la UPOLI continuemos pues "Sirviendo a la Comunidad", con buen ánimo, conscientes que nuestro trabajo al nivel que sea, tiene valor e importancia, que es parte del engranaje institucional, que todos (as) somos parte de un mismo equipo, y que somos parte de un ministerio de Dios. Así Jesús nos acompañará, inspirará y fortalecerá, y así vamos a florecer y fructificar, para el bien del pueblo nicaragüense y la gloria de Dios.

Gracia, misericordia y paz a ustedes, de Dios nuestro padre y de nuestro Señor Jesucristo.

Con especial afecto en Cristo,

\section{Equipo Pastoral UPOLI. Escuela de Teología}

Febrero 05, 2014.

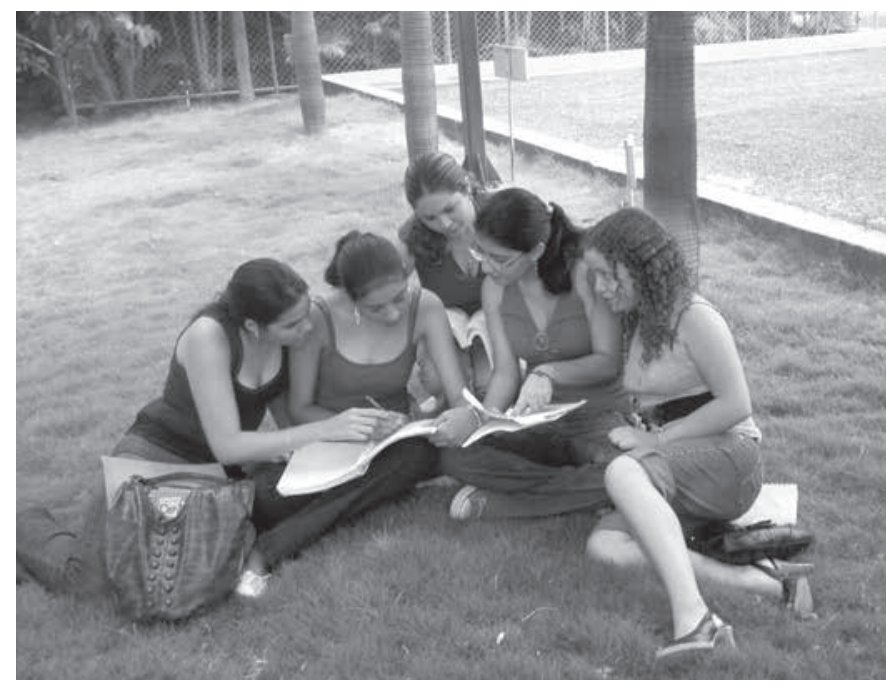

Foto: Edward Dávila 